\title{
New polymer-graphene nanocomposite electrodes with platinum-palladium nanoparticles for chemical power sources
}

\author{
N. A. Yashtulov ${ }^{1 *}$, M. V. Lebedeva ${ }^{2}$, L. N. Patrikeev ${ }^{3}$, N. K. Zaitcev ${ }^{1}$ \\ ${ }^{1}$ Department of Energy Technologies, Systems and Installations, MIREA - Russian Technological University, \\ Vernadskogo Avenue 78, 119454 Moscow, Russian Federation \\ ${ }^{2}$ Department of Physical Chemistry, MIREA - Russian Technological University, Vernadskogo Avenue 78, \\ 119454 Moscow, Russian Federation \\ ${ }^{3}$ Department of micro and nanoelectronics, National Research Nuclear University MEPhI (Moscow Engineering Physics \\ Institute), Kashirskoe road 31, 115409 Moscow, Russian Federation
}

Received 25 January 2019; accepted in revised form 25 March 2019

\begin{abstract}
In the present experimental work new polymer-reduced graphene oxide (rGO) nanocomposites with bimetallic platinum-palladium nanoparticles as functional electrodes for chemical power sources were prepared. The size and shape of nanoparticles in the composites have been studied by use of atomic force and high-resolution transmission electron microscopy techniques, X-ray phase analysis and small-angle X-ray scattering. Model tests on the basis of chemically-obtained composite electrodes under operating conditions of fuel elements with formic acid oxidation were carried out.
\end{abstract}

Keywords: polymer composites, reduced graphene oxide, platinum-palladium nanoparticles, chemical power sources, formic acid

\section{Introduction}

Creating of electrode materials with advanced specific characteristics is one of the key ways to increase the energy efficiency of chemical power sources based on fuel cells (FC). FCs are considered to be one of the alternatives to current fossil fuel operating sources. In comparison with other alternative energy sources, fuel cells are more efficient, have less emission of harmful chemical substances, exhibit silent operation and portability [1-5].

A prime objection of the FC commercialization is searching for optimal and inexpensive anode and cathode material catalysts. Platinum usually demonstrates maximum catalytic activity in the oxidation of fuels in chemical power sources. But still platinum hasn't won wide commercial availability because of the scarcity of its natural resources, high cost and catalytic poison hypersensitivity (e.g. carbon, sulfur and nitrogen oxides) during fuel cells' operation. At the same time, the development of new effective electrode catalysts for chemical power sources is considered to be an urgent task of both fundamental and applied chemistry [1-7].

In our previous works composite electrode materials with bimetallic platinum and palladium catalysts on polymer carriers, as well as on porous silicon, have been synthesized [8-13]. There was developed the technology of formation and stabilization of catalytically active platinum and palladium metal layers in aqueous-organic solutions of reversed microemulsions in the presence of anionic (AOT) and nonionic (Triton X-100) surfactants. The evaluation of the 
catalytic activity and stability of platinum and palladium bimetallic catalysts in the hydrogen and formic acid oxidation reactions in low-temperature current sources were observed. Also, the application perspectives of polymer membranes and porous silicon as matrix carriers have been demonstrated [8-20].

Recent publications have shown keen interest in the design of composite materials based on polymer membranes (e.g., Nafion membranes) and nanoparticles of various metals. These hybrid materials represent a class of nanomaterials that can combine the characteristics of metallic and polymer components in a single catalytic composite $[8,11,12,16,18,21,22]$. Carbon carriers, carbon black particularly, are standard substrate matrices for fuel cell catalysts. However, the concomitant process of carbon oxidation is metal catalysts 'poisoning' with carbon monoxide (CO), resulting in the degradation of the active layer as well as specific characteristics and service life of the fuel cell. In order to construct advanced fuel cells which have high specific power efficiency, low loading of platinum metals, increased service life, the investigations of efficient catalysts and replacement of carbon black with other matrix carriers, for example, carbon nanotubes (CNT) have been carried out [6, $13-15,17,20,23]$. Recently special attention has been paid to the development of nanocomposite materials based on graphene oxide (GO), reduced graphene oxide (rGO) [24-27].

Presently special attention is paid to the development of palladium/platinum based catalysts, for fuel cells with direct oxidation of formic acid $[6,8,10,13,14$, 17, 20, 27-31]. This type of chemical power sources has a number of advantages over other types of hydrogen-containing fuels: 1 ) fuel cells with direct oxidation of formic acid have a high open circuit potential at room temperature; 2 ) formic acid is a non-toxic liquid fuel; 3 ) in contrast to methanol, it is possible to use highly-concentrated formic acid as a high specific energy fuel; 4) formic acid is an electrolyte, therefore it can facilitate the transfer of protons inside the anode space.

The principal novelty of this work consists in the following:

- for the first time composite electrodes, obtained by chemical reduction (using nonionic surfactant Triton X-100) of platinum-palladium ions on combined reduced graphene oxide-polymer Nafion support have been formed;
- advanced specific characteristics of bimetal polymer composites in formic acid-oxygen FC with a low metal content have been received;

- optimal conditions for the metal-polymer nanocomposites synthesis have been indicated in order to reduce the crossover effect of formic acid.

In scientific publications devoted to fuel cells based on graphene oxide-Nafion support investigations, experiments have been carried out for hydrogenoxygen or methanol models [24-27]. Formic acidoxygen fuel cells studies on such hybrid polymer Nafion-reduced graphene oxide matrix have not been conducted yet. Proposed advanced technology allows to maintain the expensive platinum catalysts with increasing of fuel cell power parameters.

The aim of this work is to test formic acid-oxygen FC models based on composite electrodes, obtained by chemical reduction (using nonionic surfactant Triton X-100) of platinum and palladium ions on Nafion-reduced graphene oxide support.

\section{Experimental}

\subsection{Materials}

Chemicals used in this work were commercially available from Aldrich, Merck, Fluka or POCH and used as received, unless otherwise stated. Pristine graphite (JSC NIIGraphite, Russia) [32] was used as a precursor material for $\mathrm{rGO}$ synthesis.

\subsection{Characterizations}

The size and form of platinum metal nanoparticles were estimated by means of atomic force microscopy (AFM) using the N-Tegra Prima microscope (NT MDT, Russia). Ultrasonic treatment was carried out on an UD150SH-6L Ultrasonic Cleaner ultrasonic disperser (Eumax, Germany). The surface morphology of platinum-palladium nanocomposites on polymer-reduced graphene oxide was studied through scanning electron microscopy (SEM) at JSM-7401F (Jeol, Japan) instrument with the INCA analyzer (Oxford Instruments, England) and high-resolution transmission electron microscopy (HRTEM), using Zeiss Libra 200FE (Carl Zeiss, Germany). The molar ratio of the metals in the nanocomposites was determined by atomic adsorption spectroscopy (AAS) on a Kvant Z-Eta spectrometer (Akvilon, Russia). X-ray diffraction (XRD) patterns were recorded on diffractometer D8 FOCUS (Bruker AXS, Germany) using $\mathrm{Cu} \mathrm{K} \alpha$ radiation sources, operated at $30 \mathrm{kV}$ and $30 \mathrm{~mA}$. The 
small-angle X-ray scattering (SAXS) experiments were performed at a specialized SAXSess diffractometer (Anton Paar, Austria) in a vacuum chamber at room temperature using monochromatic $\mathrm{Cu} \mathrm{K \alpha}$ radiation. Small-angle X-ray scattering was measured in the transmission geometry, the sample was placed in a non-scattering adhesive tape. Volt-ampere and watt-ampere tests of the formed electrode materials were carried out at the Fuel Cell Test System 850C (Scribner Associates Inc., USA).

\subsection{Nanoparticles synthesis and nanocomposites formation}

Bimetallic platinum - palladium nanoparticles (NPs) were synthesized by chemical reduction of sodium tetrahydroborate $\mathrm{NaBH}_{4}(98 \%$, Merck, Germany) in solutions of reversed microemulsions [8-13], using nonionic surfactant-Triton X-100. The method of solution preparation was as follows: an aqueous-organic solution of a mixture of two salts of platinum $\mathrm{H}_{2} \mathrm{PtCl}_{6}$ and palladium $\left[\mathrm{Pd}\left(\mathrm{NH}_{3}\right)_{2}\right] \mathrm{Cl}_{2}$ (Sigma Aldrich, USA) was prepared. To form a microemulsion medium, 0.15 M solution of Triton X-100 (Sigma Aldrich, USA) and propanol-2 was used. Then, a microemulsion of similar composition, contained $0.1 \mathrm{M}$ water solution of the reducing agent $-\mathrm{NaBH}_{4}$, was added to this solution under ultrasonic action for $2-3 \mathrm{~min}$. In the process of mixing the two emulsions, platinum and palladium ions were simultaneously reduced in the water pools of micelles - microreactors. The molar water/surfactant ratio $(\omega)$ while making the experiments was changed from 1.5 to 8 . In order to prevent the sunlight destruction of nanoparticles, the solutions of microemulsions were stored in darkness at room temperature. The molar ratios of platinum metals in bimetallic Pt-Pd nanoparticles ranged from 1:7 to $5: 1$.

Figure 1 shows the well-known reduced graphene oxide preparation method, described by Tkachev et al. [33] and used in present work. RGO synthesis includes oxidation of graphite by $\left(\mathrm{NH}_{4}\right)_{2} \mathrm{~S}_{2} \mathrm{O}_{8}$ in $\mathrm{H}_{2} \mathrm{SO}_{4}$ and subsequent oxidation of the product by $\mathrm{KMnO}_{4}$ in $\mathrm{H}_{2} \mathrm{SO}_{4}$ and by $30 \% \mathrm{H}_{2} \mathrm{O}_{2}$.

Metal-polymer films of Nafion (Nf) membranes with bimetallic Pt-Pd nanoparticles were synthesized as described in $[8,11,12]$. The perfluorinated membrane of the Nafion 115 type (Sigma Aldrich, USA) with a thickness of $0.127 \mathrm{~mm}$ was used for the formation of the metal-polymer films. The solubilization of solutions was performed on an Ultrasonis Cleaner

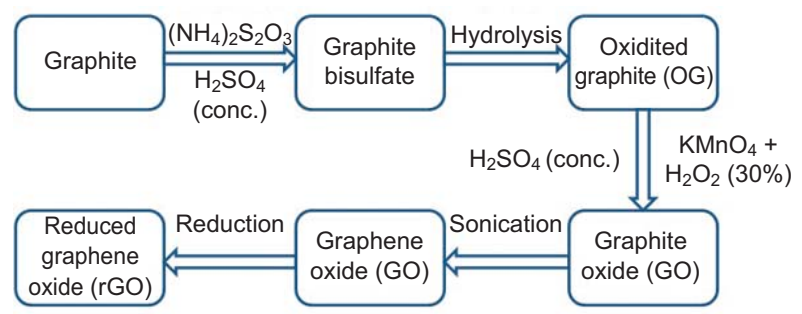

Figure 1. rGO preparation scheme

UD150SH-6L ultrasonic disperser (Eumax, Germany). For obtaining the metal-polymer films, the samples of the Nafion membranes were placed in cells with a reverse microemulsion solution with PtPd nanoparticles and solution was sonicated during 3-5 minutes. After that, the modified metal-polymer membrane was washed to remove the excess surfactant and the organic solvent.

To obtain combined metal-polymer films with rGO, the modified Nafion membrane modified with Pt-Pd nanoparticles was immersed in an aqueous solution of propanol-2 and glycerol (Merck, Germany) the addition of rGO. The resulting suspension was sonicated for 10-15 min. The homogeneous suspension containing the required amount of platinum metals, the polymer, and rGO was dried on a glass substrate at $70^{\circ} \mathrm{C}$ in an argon atmosphere. The obtained rGO$\mathrm{Pt}-\mathrm{Pd} / \mathrm{Nafion}$ composites were then hot pressed at $120^{\circ} \mathrm{C}$ to assure good adhesion between $\mathrm{rGO}$ and the Nafion membrane. In order to clean the electrodes from traces of surfactant and solvent, NafionrGO samples with Pt-Pd nanoparticles were washed in isooctane, ethanol and distilled water.

\section{Results and discussion}

A study of the sizes and shapes of platinum-palladium nanoparticles was carried out by atomic force microscopy (AFM). Metal nanoparticles were analyzed on mica, which is a standard substrate for such measurements. Figure 2 shows an example of bimetallic Pt-Pd nanoparticles AFM image obtained at metal ratio of $1: 1$ and solubilization coefficient $\omega=$ 3. One can observe the formation of both spherical and ellipsoidal Pt-Pd nanoparticles, the average size of which is from 4.5 to $6 \mathrm{~nm}$. With increasing the palladium content and solubilization coefficient the nanoparticles' size rises up to $8-10 \mathrm{~nm}$.

Due to the possibility of controling and to stabilizing nanoparticles' size, special attention should be paid to the above mentioned methods of obtaining metal nanoparticles in aqueous-organic solutions 


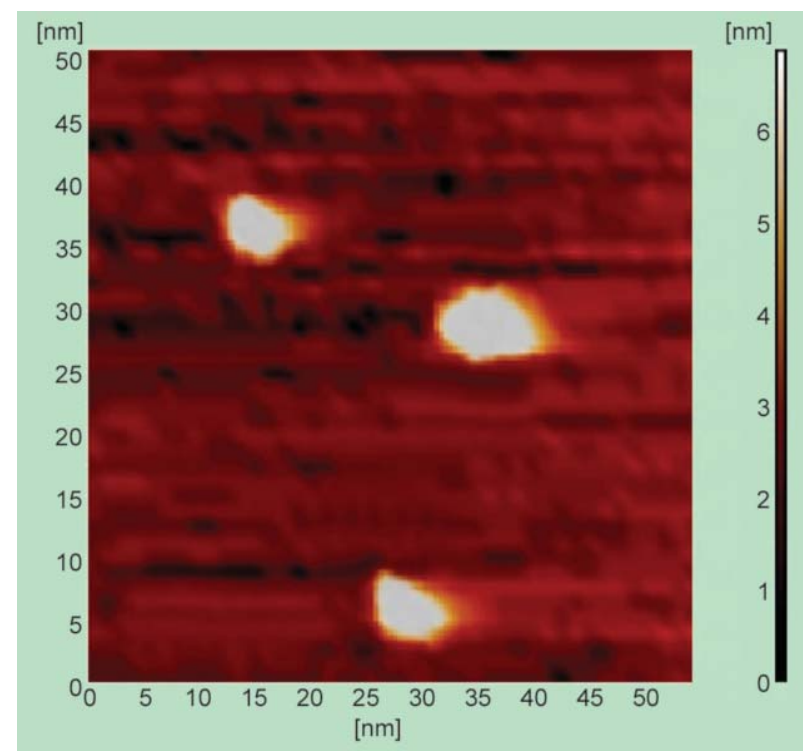

Figure 2. AFM image of Pt-Pd NPs at $\omega=3(6-7 \mathrm{~nm})$.

with subsequent nanocomposites formation on functional matrix substrates. Reduced graphene oxide, because of its high surface area, is the most effective carrier matrix for the composite materials formation with metal nanoparticles. On the basis of catalytic platinum metal composites with rGO, current sources with increased specific characteristics have been constructed [24-27].

Platinum-palladium nanocomposites were formed in microemulsion solutions with nonionic surfactant (Triton X-100) in contact with rGO. Figure 3 shows a SEM image of Pt-Pd(1:5)/Nf-rGO nanocomposites formed at $\omega=1.5$. Because $\mathrm{rGO}$ is hydrophilic and is highly compatible for forming ionic-conducting composite membranes, the protons released from the $\mathrm{COOH}$ groups on the basal plane of rGO sheets represent the key factor in the ionic conductivity of the rGO additive of the membrane. Hot-pressing treatment improved the interfacial bonding between the

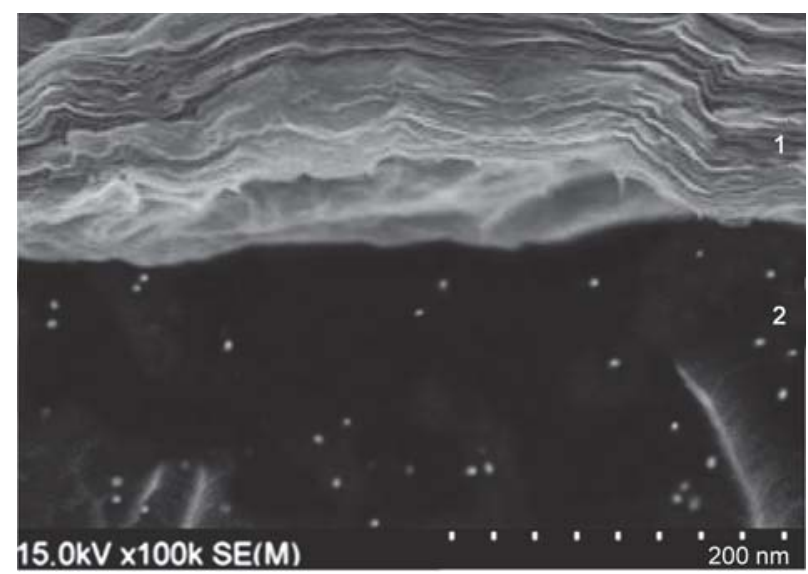

Figure 3. SEM image of Pt-Pd(1:5)/Nf-rGO composite: 1 - rGO layer, $2-\mathrm{Pt}-\mathrm{Pd} / \mathrm{Nafion}$ layer.

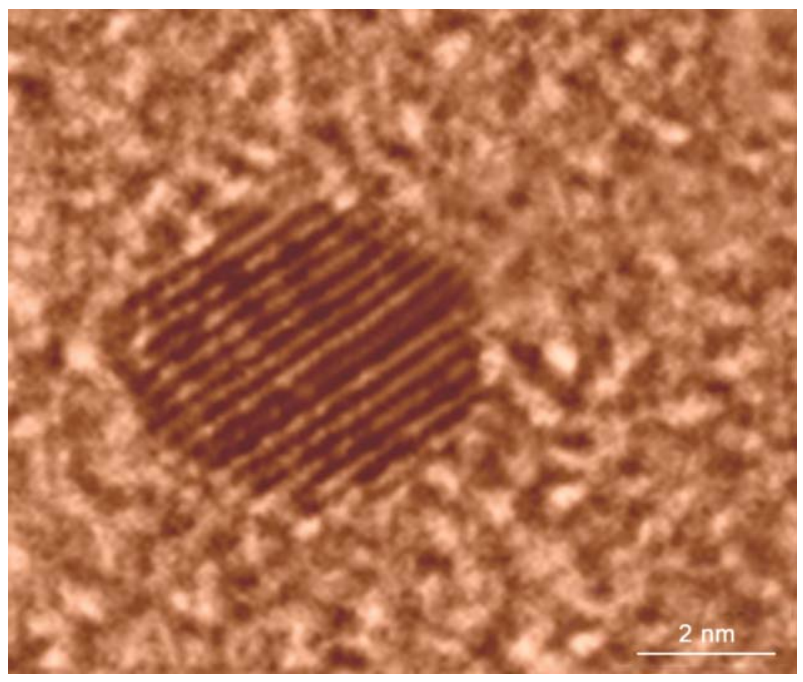

Figure 4. HRTEM micrograph of $\mathrm{Pt}-\mathrm{Pd}(1: 5) / \mathrm{Nf}-\mathrm{rGO}$ nanocomposites at $\omega=1.5$.

Nafion and the rGO sheets. Without proper hotpressing treatment, rGO disintegrated from the Nafion membrane when the composite was immersed in water.

Figure 4 demonstrates a HRTEM micrograph of Pt$\operatorname{Pd}(1: 5) / \mathrm{Nf}-\mathrm{rGO}$ nanocomposites formed at $\omega=1.5$. It can be seen that Pt-Pd NPs size in Nafion-rGO composite are $4-5 \mathrm{~nm}$.

In Table 1 the comparison of the nanocomposites' size distribution based on Nafion-rGO and Nafion, modified by Pt-Pd NPs is presented.

Thus, according to Table 1 we may conclude that the minimum size of platinum-palladium nanoparticles in nanocomposite materials is achieved by using Nafion-rGO support and the least degree of solubilization $\omega=1.5$. Due to the large specific surface area reduced graphene oxide further stabilizes the platinum-palladium nanoparticles, so there is no aggregation, as it happens with pure Nafion membrane.

The microstructures of the Nafion-rGO composite membranes were comprehensively investigated by

Table 1. Comparison of the nanocomposites' size distribution based on Nafion-rGO and Nafion modified by Pt-Pd nanoparticles (HRTEM data).

\begin{tabular}{|c|c|c|c|c|}
\hline \multirow[t]{2}{*}{ Support } & \multirow[t]{2}{*}{ Pt:Pd } & \multicolumn{3}{|c|}{$\begin{array}{c}d \\
{[\mathrm{~nm}]}\end{array}$} \\
\hline & & $\omega=1.5$ & $\omega=3$ & $\omega=5$ \\
\hline \multirow{3}{*}{ Nafion-rGO } & $5: 1$ & $3.3-4.6$ & $3.7-4.9$ & $4.1-5.2$ \\
\hline & $1: 1$ & $4.0-5.1$ & $4.5-5.6$ & $5.4-6.3$ \\
\hline & $1: 5$ & $4.5-5.7$ & $4.8-6.0$ & $5.6-7.0$ \\
\hline \multirow{3}{*}{ Nafion } & $5: 1$ & $3.7-5.0$ & $4.1-5.4$ & $4.5-5.8$ \\
\hline & $1: 1$ & $4.3-5.5$ & $4.9-6.0$ & $5.7-6.9$ \\
\hline & $1: 5$ & $4.9-6.2$ & $5.3-6.6$ & $5.8-7.4$ \\
\hline
\end{tabular}


SAXS, as shown in Figure 5. The scattering maximum of SAXS, the ionomer peak, is typically observed at $1-2 \mathrm{~nm}^{-1}$ of the scattering vector $(q)$, following this Equation (1) [33]:

$q=\frac{4 \pi \cdot \sin \theta}{\lambda}$

where $2 \theta$ is the scattering angle and $\lambda$ is wavelength. The Bragg spacing of $d$, which corresponds to the size of the ionic cluster, is inversely proportional to $q$ as $d=2 \pi / q$. The pristine Nafion membrane showed a broad peak with a $q$ value of $1.27 \mathrm{~nm}^{-1}$, which is in good agreement with literature data [18]. When rGO were incorporated into Nafion membranes, the $q$ values increased. These results indicate that the ionic clusters shrunk with the incorporation of $\mathrm{rGO}$ sheets due to reorganization through interactions between the sulfonic groups of Nafion and the hydrophilic groups of rGO.

The phase composition of nanocomposites was studied by means of X-ray phase analysis (XPA). Figure 6 presents the diffractogram of bimetallic Pt-Pd nanoparticles in the Nafion-rGO composition. On diffractogram for bimetallic nanocomposites with Pt-Pd at a metal ratio in the range from 1:7 to $5: 1$, four detected characteristic reflexes may be attributed to bimetallic platinum-palladium nanoparticles at: $\theta=$ $39.8^{\circ}$ (111), $\theta=46.3^{\circ}$ (200), $\theta=68.6^{\circ}$ (220), $\theta=$ $81.8^{\circ}(311)[10,19,20]$. Since Pt and Pd have the same crystal structure $(\mathrm{Fm} 3 \mathrm{~m})$ and similar lattice parameters (face-centered cubic, $a=3.92400$ and $3.99100 \AA$, respectively), the peaks of Pt-Pd/CNTbased nanocomposites on diffractograms are much the same as similar peaks for $\mathrm{Pt}$ and $\mathrm{Pd}-\mathrm{CNT}$

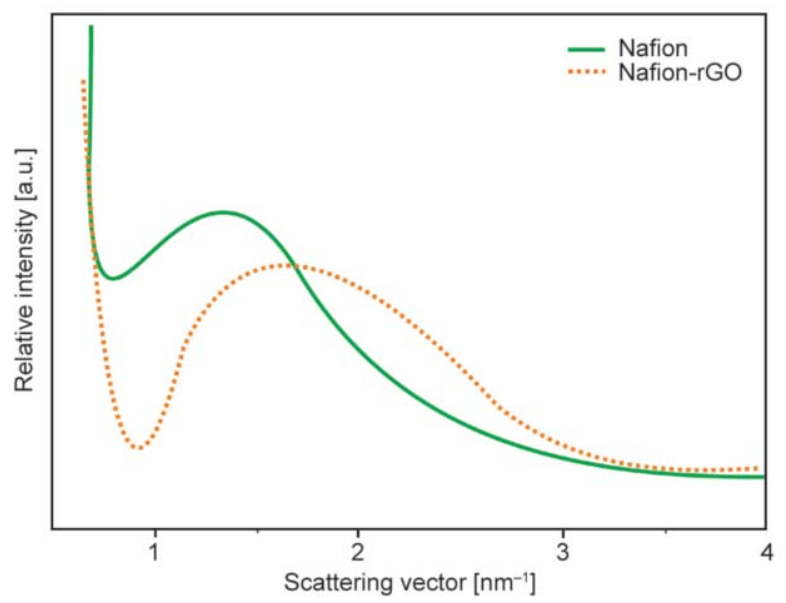

Figure 5. SAXS curves of Nafion and Nafion-rGO membranes with Pt-Pd(1:5) NPs at $\omega=1.5$.

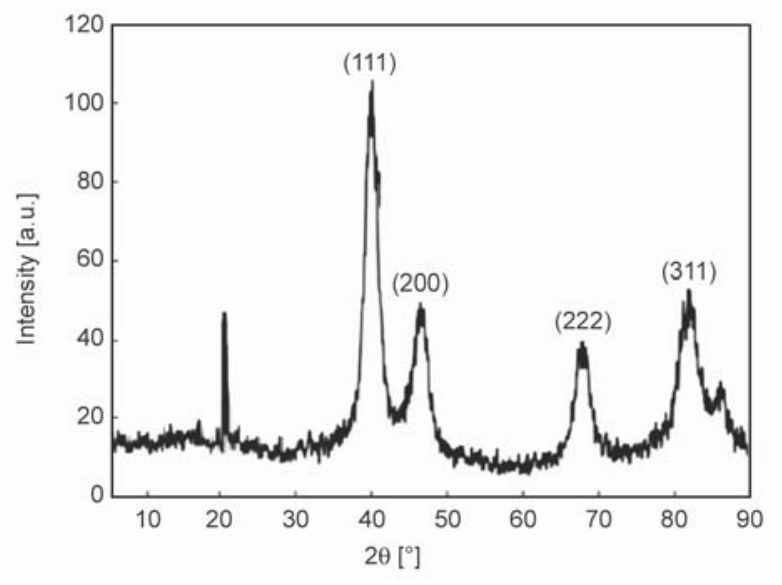

Figure 6. Diffractogram of Pt-Pd nanocomposites based on Nafion-rGO. Metal ratio of 5:1 and a solubilization coefficient $\omega=1.5$.

monometallic composites. A slight shift of typical Pt peaks towards large values of angles as well as a noticeable broadening of the bands is not worth our notice. In addition, for bimetallic platinum-palladium nanoparticles (5:1), a significantly higher intensity of the Pt-Pd peak (111) is seen in diffractogram $[19,20]$. It is seen from the X-ray patterns that for $\mathrm{rGO}$ the main peak being observed at $2 \theta \approx 23-24^{\circ}$ [34].

The results of the calculation of the coherent scattering region of Pt-Pd nanocomposites practically coincided with the data on the sizes of nanoparticles obtained with the high-resolution transmission electron microscopy (Figure 4, Table 1). The size of bimetallic Pt-Pd nanoparticles at varying metal ratios from 1:7 to 5:1 in the composition of carbon carriers ranged from 3 to $9 \mathrm{~nm}$.

The data of energy-dispersive X-ray spectroscopy (EDXS) were obtained for Pt-Pd nanoparticles synthesized at $\omega=5$ on the surface of Nafion-rGO. The EDX spectrum of the nanocomposite membrane clearly shows the presence of Pt and Pd, next to other elements, like fluorine, carbon and oxygen. The results (Table 2, Figure 7) for an initial ratio of platinum metals of $1: 1$ demonstrated that Pt-Pd(1:1)/Nf-rGO nanocomposite contains (in molar per cent) $92.5 \%$

Table 2. Elemental composition of Pt-Pd(1:1)/Nafion-rGO at $\omega=5$.

\begin{tabular}{|c|c|c|}
\hline Element & Intensity & $\begin{array}{c}\text { Atomic } \\
{[\%]}\end{array}$ \\
\hline $\mathrm{C}$ & 1680.3 & 92.5 \\
\hline $\mathrm{O}$ & 31.2 & 3.9 \\
\hline $\mathrm{F}$ & 24.6 & 1.5 \\
\hline $\mathrm{Pt}$ & 9.4 & 1.1 \\
\hline $\mathrm{Pd}$ & 17.8 & 1.0 \\
\hline Total & & 100.0 \\
\hline
\end{tabular}




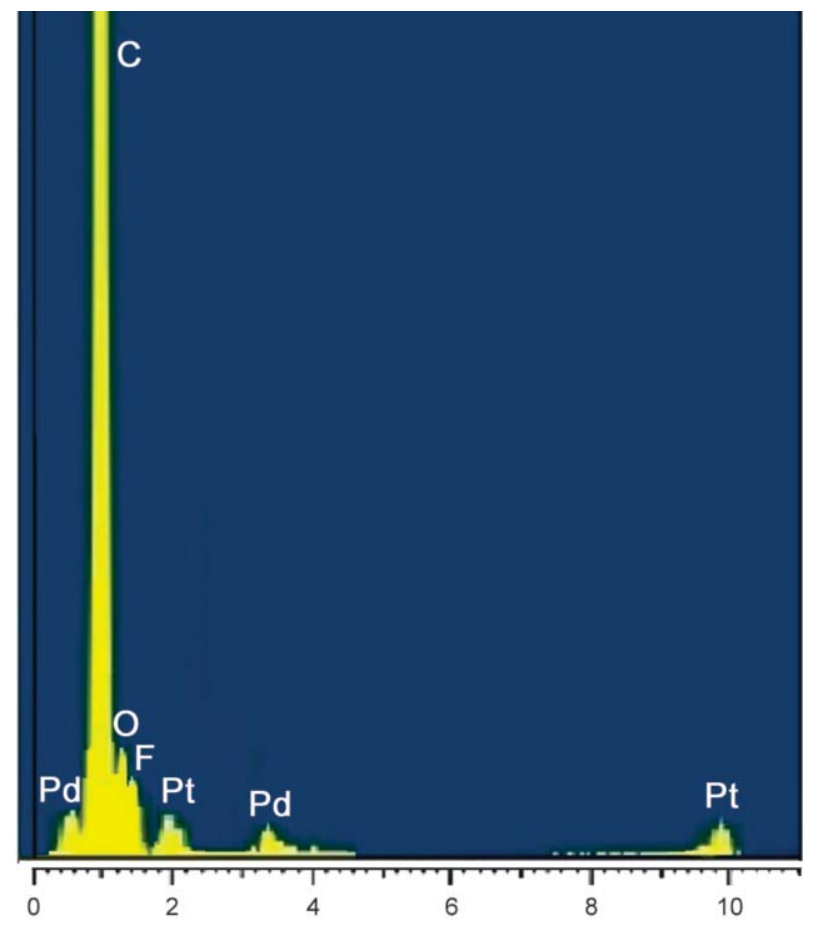

Full scale 5300 cts cursor: $0.000 \mathrm{keV}$

Figure 7. EDX spectrum of the Pt-Pd/Nf-rGO composite.

of carbon, $1.1 \%$ of platinum, and $1.0 \%$ of palladium. These data prove the production of Pt-Pd(1:1)/NfrGO nanocomposites corresponding to the metal ratio in solutions of precursors and can testify to the absence of oxide forms on the metals and carbon surfaces. The EDXS data corresponded with AAC method data.

For FC with direct oxidation of formic acid, the electrooxidation reaction proceeds in two ways: direct oxidation without the formation of carbon monoxide (Equation (2)) and indirect oxidation with the formation of a by-product - adsorbed CO molecules (Equation (3)):

$\mathrm{HCOOH} \rightarrow \mathrm{COOH}+\mathrm{H}^{+}+\overline{\mathrm{e}} \rightarrow \mathrm{CO}_{2}+2 \mathrm{H}^{+}+2 \overline{\mathrm{e}}$

$\mathrm{HCOOH} \rightarrow \mathrm{CO}_{\mathrm{ads}}+\mathrm{H}_{2} \mathrm{O} \rightarrow \mathrm{CO}_{2}+2 \mathrm{H}^{+}+2 \overline{\mathrm{e}}$

The process of oxidative dehydrogenation of formic acid (Equation (2)) is mainly typical for palladium catalysts. Indirect oxidation (Equation (3)) predominates in platinum-based catalysts [10, 17, 19, 20, 27].

In this work, the models of formic acid-oxygen fuel elements have been tested on the basis of carbon nanotube composite electrodes with platinum-palladium particles. The membrane-electrode assemble consisted of a polymer membrane Nafion-115 pressed at a temperature of $85^{\circ} \mathrm{C}$ [35] between the composite anode and cathode based on reduced graphene oxide. Pt-Pd nanoparticles when metal loading $\left(m_{\mathrm{s}}\right)$ was of $0.8-1.3 \mathrm{mg} / \mathrm{cm}^{2}$ on rGO-Nafion served as anode, rGO-Nafion with Pt nanoparticles when metal loading $\left(m_{\mathrm{s}}\right)$ was $0.5 \mathrm{mg} / \mathrm{cm}^{2}$ served as cathode, the process temperature was $25^{\circ} \mathrm{C}$. For the study of volt-and watt-ampere dependences, four types of models with constant (concentration of formic acid of $5 \mathrm{M}$ and process temperature of $25 \pm 1^{\circ} \mathrm{C}$ ) and variable characteristics (catalyst loading, a different ratio of metals and a type support) were made:

Model 1: platinum-palladium catalyst loading $\left(m_{\mathrm{s}}\right)$ was $1.3 \mathrm{mg} / \mathrm{cm}^{2}$, Pt:Pd ratio was $1: 5$, average nanoparticles diameter $-4.5-6 \mathrm{~nm}$, Nafion-rGO electrodes;

Model 2: platinum-palladium catalyst loading $\left(m_{\mathrm{s}}\right)$ was $0.8 \mathrm{mg} / \mathrm{cm}^{2}$, Pt:Pd ratio was $1: 5$, average nanoparticles diameter $-4.5-6 \mathrm{~nm}$, Nafion-rGO electrodes;

Model 3: platinum-palladium catalyst loading $\left(m_{\mathrm{s}}\right)$ was $1.3 \mathrm{mg} / \mathrm{cm}^{2}$, Pt:Pd ratio was $1: 5$, average nanoparticles diameter $-5-6 \mathrm{~nm}$, Nafion electrodes;

Model 4: platinum-palladium catalyst loading $\left(m_{\mathrm{s}}\right)$ was $1.3 \mathrm{mg} / \mathrm{cm}^{2}$, Pt:Pd ratio was $1: 1$, average nanoparticles diameter $-4-5 \mathrm{~nm}$, Nafion-rGO electrodes.

In the literature there are no data on the study of fuel cells with direct oxidation of formic acid using combined polymer-reduced graphene oxide supports. Besides there is no experimental data on the creation of bimetallic platinum-palladium catalysts based on such combined matrices. In this connection the results obtained in this work are new and undoubtedly practically significant for development of effective materials on the basis of polymers.

Figure 8 shows the current - voltage characteristics $(U-j)$ of models $N^{o} 1-N^{o}-4$. As a result of carried out tests, model № 4 (Figure 8 curve № 4 ) showed the smallest specific characteristics because of low palladium content in the nanocomposite electrode, due to which the formation of carbon monoxide $\mathrm{CO}$ according to Equation (3) and degradation of electrodes with high platinum content occurs.

The model 3, formed on the basis of rGO electrodes (Figure 8 curve №3), shows the worst characteristics, in comparison with the similar models (Figure 8 curves № 1 and №2), developed on the basis of 


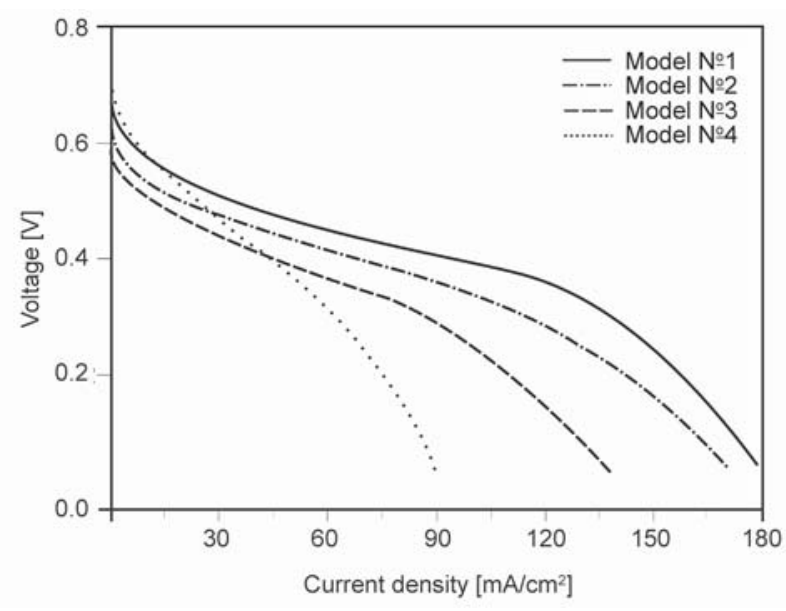

Figure 8. Volt-ampere characteristics of laboratory models № $1-\mathrm{N}-4$ for fuel cell membrane-electrode assemblies.

Nafion-rGO electrodes. This fact may be explained by the presence of $\pi$-electrons, which play an important role in the interaction of graphene structures with platinum metal nanoparticles. Accelerated delocalization of the electron density amplifies the coupling of rGO with catalyst metals and increases the specific characteristics of catalysts. In this regard, we conclude that the best energy characteristics of the four variants of the fuel cell layouts have been obtained by using electrodes based on Nafion-rGO, loading platinum catalysts $1.3 \mathrm{mg} / \mathrm{cm}^{2}$ and a platinum-palladium ratio of 1:5. The maximum current density was $130-140 \mathrm{~mA} / \mathrm{cm}^{2}$ in the operating voltage range $0.4-0.6 \mathrm{~V}$.

According to Figure 9 there is a maximum specific power for all four models of membrane-electrode assemblies of fuel cells while increasing current density. The best energy characteristics have been obtained by using electrodes based on Nafion-rGO with

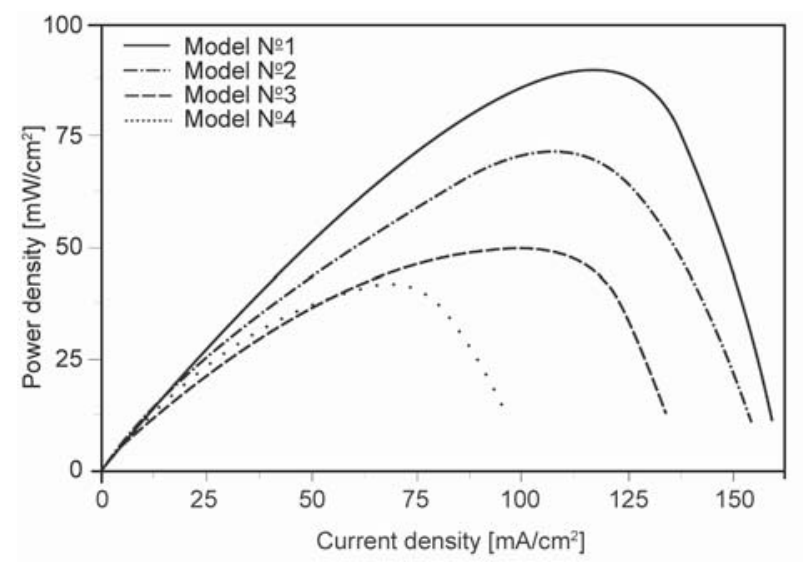

Figure 9. Watt-current characteristics of laboratory models № $1-\mathrm{N}$ - 4 for fuel cell membrane-electrode assemblies. a catalyst load of $1.3 \mathrm{mg} / \mathrm{cm}^{2}$. The maximum specific power was $79 \pm 3 \mathrm{~mW} / \mathrm{cm}^{2}$ with a current density of $130 \pm 10 \mathrm{~mA} / \mathrm{cm}^{2}$. While increasing the current density of more than $140 \mathrm{~mA} / \mathrm{cm}^{2}$, there has been observed a sharp decrease in the specific power, associated with the increase of polarization losses of $\mathrm{FC}$ with direct oxidation of formic acid $[6-8,36]$.

The maximum value of the current density proportional to the reaction rate has been observed in electrode materials based on Nafion-rGO and modified by bimetallic Pt:Pd nanoparticles at a ratio of 1:5. A further increase in the palladium content in nanocomposites to 1:7 causes a decrease in the specific characteristics while the testing of FC models. The cause of this process probably is less catalytic activity and corrosion resistance of $\mathrm{Pd}$ compared to $\mathrm{Pt}$ that was observed in the direct oxidation of formic acid. The main advantage of the proposed electrode materials is low crossover effect of formic acid in fuel cells [7, $26,36,37]$ - this is proved by high current density and specific power.

Also there has been observed the increase of catalytic activity in the formic acid oxidation reaction (platinum catalysts loading was increased to value of 1.2$1.3 \mathrm{mg} / \mathrm{cm}^{2}$ ), and that affected both the increase in the current density and the power of the fuel cells. Further increase of catalyst loading on carbon nanotubes (more than $1.7 \mathrm{mg} / \mathrm{cm}^{2}$ ) lead to increasing the size of bimetallic Pt-Pd nanoparticles up to 10 $17 \mathrm{~nm}$ and causes a significant reduction in current density and power.

Thus, the choice of the optimal platinum catalysts ratio in the formic acid-oxygen membrane-electrode assemblies while operation and catalyst nanoparticles size reducing lead to increasing of the FC specific power at a given current density.

To compare the obtained power characteristics with analogous systems the Table 3 is presented. As it can be seen the formed composites have high specific power both under similar conditions of FC investigation (3-5 M HCOOH) with other works which confirms the advantages of the created materials. It is worth noting that Kivrak et al. [7] had been proposed Pd-containing catalysts on multiwall carbon nanotube for direct formic acid fuel cell performances. As a result current density parameters in $5 \mathrm{M}$ $\mathrm{HCOOH}$ (platinum and palladium catalyst loading was $4 \mathrm{mg} / \mathrm{cm}^{2}$ ) at 18,30 and $60^{\circ} \mathrm{C}$ was about 5.6 , 17 and $44 \mathrm{~mA} / \mathrm{cm}^{2}$, which is significantly less than the results obtained in our work. The achievement 
Table 3. Summary of the performance of formic-acid fuel cells available in the literature as well as the $\mathrm{Pt}-\mathrm{Pd} / \mathrm{Nafion}-\mathrm{rGO}$ of this work.

\begin{tabular}{|l|c|c|c|c|}
\hline \multicolumn{1}{|c|}{ Ref. } & $\begin{array}{c}\text { Anode } \\
{\left[\mathbf{m g} / \mathbf{c m}^{2}\right]}\end{array}$ & $\begin{array}{c}\text { Cathode } \\
{\left[\mathbf{m g} / \mathbf{c m}^{2}\right]}\end{array}$ & $\begin{array}{c}\text { Power } \\
\mathbf{d e n s i t y} \\
{\left[\mathbf{m W} / \mathbf{c m}^{2}\right]}\end{array}$ & $\begin{array}{c}\text { Temperature } \\
{\left[{ }^{\circ} \mathbf{C}\right]}\end{array}$ \\
\hline$[26]$ & 2 & 1 & 245 & 60 \\
\hline This work & 1.3 & 0.5 & 82 & 25 \\
\hline This work & 1.3 & 0.5 & 289 & 60 \\
\hline$[36]$ & 0.5 & 4 & 80 & 25 \\
\hline This work & 0.5 & 3.5 & 95 & 25 \\
\hline$[37]$ & 1 & 1 & 25 & 25 \\
\hline This work & 0.5 & 0.5 & 64 & 25 \\
\hline
\end{tabular}

of improved fuel cell performance in this work is explained by low crossover effect of formic acid and the absence of carbon monoxide formation on the electrode surface by Equation (2) $[8,38]$.

Therefore, new composite materials obtained in our work have demonstrated higher specific values of power and current density specific parameters per unit mass of platinum catalysts for similar electrochemical systems [7, 26, 36-38], presented to date.

\section{Conclusions}

In the present work new effective polymer-containing composite electrodes, obtained by chemical reduction (using nonionic surfactant - Triton X-100) of platinum-palladium ions on reduced graphene oxide-Nafion support have been formed. The membrane electrode assembly models of fuel cells with direct formic acid oxidation on the basis of formed nanocomposite have been investigated. It has been found that the maximum specific power and current density are achieved under following conditions: platinum metals loading is $1.3 \mathrm{mg} / \mathrm{cm}^{2}$, platinum: palladium ratio is $1: 5$ and when using combined polymer Nafion-reduced graphene oxide support.

\section{Acknowledgements}

This work is supported by state assignment of the Russian Federation (project № 13.3140.2017/PCh).

\section{References}

[1] Dicks A., Rand D. A. J.: Fuel cell systems explained. Wiley, London (2018).

[2] Gandia L. M., Arzamedi G.: Renewable hydrogen technologies: Production, purification, storage, applications and safety. Elsevier, Amsterdam (2013).
[3] Stolten D., Emonts B.: Fuel cell science and engineering: Materials, processes, systems and technology. Wiley, London (2012).

[4] Ozoemena K. I., Chen S.: Nanomaterials for fuel cell catalysis. Springer, Berlin (2016).

[5] Goodarzi G. A., Hayes J. G.: Electric powertrain: Energy systems, power electronics and drives for hybrid, electric and fuel cell vehicles. Wiley, London (2018).

[6] Caglar A., Sahan T., Cogenli M. S., Yurtcan A. B., Aktas N., Kivrak H.: A novel central composite design based response surface methodology optimization study for the synthesis of Pd/CNT direct formic acid fuel cell anode catalyst. International Journal of Hydrogen Energy, 43, 11002-11011 (2018).

https://doi.org/10.1016/j.ijhydene.2018.04.208

[7] Kivrak H., Atbas D., Alal O., Çögenli M. S., Bayrakceken A., Mert S. O., Sahin O.: A complementary study on novel PdAuCo catalysts: Synthesis, characterization, direct formic acid fuel cell application, and exergy analysis. International Journal of Hydrogen Energy, 43, 21886-21898 (2018). https://doi.org/10.1016/j.ijhydene.2018.09.135

[8] Yashtulov N. A., Lebedeva M. V., Myasnikova N. V., Ragutkin A. V., Flid V. R.: The catalytic activity of bimetallic Pt-Pd polymer nanocomposites in formic acid oxidation. Russian Chemical Bulletin, 66, 474-478 (2017).

https://doi.org/10.1007/s11172-017-1757-0

[9] Yashtulov N. A., Lebedeva M. V., Ragutkin A. V., Zaitsev N. K.: Electrode materials based on porous silicon with platinum nanoparticles for chemical current sources. Russian Journal of Applied Chemistry, 91, 280-285 (2018).

https://doi.org/10.1134/S1070427218020167

[10] Yashtulov N. A., Patrikeev L. N., Zenchenko V. O., Lebedeva M. V., Zaitsev N. K., Flid V. R.: Palladiumplatinum-porous silicon nanocatalysts for fuel cells with direct formic acid oxidation. Nanotechnologies in Russia, 11, 562-568 (2016). https://doi.org/10.1134/S1995078016050207

[11] Lebedeva M. V., Antropov A. P., Ragutkin A. V., Yashtulov N. A.: The electrode materials based on carbon nanotubes and polymer matrix modified with platinum catalysts for chemical power sources. International Journal of Applied Engineering Research, 13, 16774-16777 (2018).

[12] Lebedeva M. V., Yashtulov N. A., Flid V. R.: Catalysts with platinum-palladium nanoparticles on polymer matrix supports. Kinetics and Catalysis, 57, 847-852 (2016). https://doi.org/10.1134/S0023158416060070

[13] Yashtulov N. A., Lebedeva M. V., Pestov S. M.: Catalysts for anode oxidation of formic acid on carbon nanotubes 'Taunit' (in Russian). Fine Chemical Technologies, 11, 59-64 (2016). 
[14] Malolepszy A., Mazurkiewicz M., Stobinski L., Lesiak B., Kövér L., Tóth J., Mierzwa B., Borodzinski A., Nitzee F., Wågberg T.: Deactivation resistant $\mathrm{Pd}-\mathrm{ZrO}_{2}$ supported on multiwall carbon nanotubes catalyst for direct formic acid fuel cells. International Journal of Hydrogen Energy, 40, 16724-16733 (2015).

https://doi.org/10.1016/j.ijhydene.2015.08.048

[15] Muneeb O., Chino I., Saenz A., Haan J. L.: An ascorbate fuel cell with carbon black nanoparticles as anode and cathode. Journal of Power Sources, 413, 216-221 (2019). https://doi.org/10.1016/j.jpowsour.2018.12.042

[16] Ahmed M., Attard G. A., Wright E., Sharman J.: Methanol and formic acid electrooxidation on nafion modified $\mathrm{Pd} / \mathrm{Pt}\left\{\begin{array}{lll}1 & 1 & 1\end{array}\right\}$ : The role of anion specific adsorption in electrocatalytic activity. Catalysis Today, 202, 128-134 (2013). https://doi.org/10.1016/j.cattod.2012.05.014

[17] Rojas J. V., Castano C. H.: Production of palladium nanoparticles supported on multiwalled carbon nanotubes by gamma irradiation. Radiation Physics and Chemistry, 81, 16-21 (2012).

https://doi.org/10.1016/j.radphyschem.2011.08.010

[18] Battirola L. C., Schneider J. F., Torriani I. C. L., Tremiliosi-Filho G.: Improvement on direct ethanol fuel cell performance by using doped-Nafion ${ }^{\circledR} 117$ membranes with $\mathrm{Pt}$ and $\mathrm{Pt}-\mathrm{Ru}$ nanoparticles. International Journal of Hydrogen Energy, 38, 12060-12068 (2013). https://doi.org/10.1016/j.ijhydene.2013.06.126

[19] Hong P., Zhong Y., Liao S., Zeng J., Lu X., Chen W.: A 4-cell miniature direct formic acid fuel cell stack with independent fuel reservoir: Design and performance investigation. Journal of Power Sources, 196, 5913-5917 (2011). https://doi.org/10.1016/j.jpowsour.2011.03.014

[20] Winjobi O., Zhang Z., Liang C., Li W.: Carbon nanotube supported platinum-palladium nanoparticles for formic acid oxidation. Electrochimica Acta, 55, 4217 4221 (2010).

https://doi.org/10.1016/j.jpowsour.2011.03.014

[21] Hasanabadi N., Ghaffarian S. R., Hasani-Sadrabadi M. M.: Nafion-based magnetically aligned nanocomposite proton exchange membranes for direct methanol fuel cells. Solid State Ionics, 232, 58-67 (2013).

https://doi.org/10.1016/j.ssi.2012.11.015

[22] Ru C., Gu Y., Duan Y., Zhao C., Na H.: Enhancement in proton conductivity and methanol resistance of Nafion membrane induced by blending sulfonated poly(arylene ether ketones) for direct methanol fuel cells. Journal of Membrane Science, 573, 439-447 (2019). https://doi.org/10.1016/j.memsci.2018.12.030

[23] He X., Luan S. Z., Wang L., Wang R. Y., Du P., Xu Y. Y., Yang H. J., Wang Y. G., Huang K., Lei M.: Facile loading mesoporous $\mathrm{Co}_{3} \mathrm{O}_{4}$ on nitrogen doped carbon matrix as an enhanced oxygen electrode catalyst. Materials Letters, 244, 78-82 (2019).

https://doi.org/10.1016/j.matlet.2019.01.144
[24] Dong L., Gari R. R. S., Li Z., Craig M. M., Hou S.: Graphene-supported platinum and platinum-ruthenium nanoparticles with high electrocatalytic activity for methanol and ethanol oxidation. Carbon, 48, 781-787 (2010).

https://doi.org/10.1016/j.carbon.2009.10.027

[25] Abouzari-Lotf E., Zakeri M., Nasef M. M., Miyake M., Mozarmnia P., Bazilah N. A., Emelin N. F., Ahmad A.: Highly durable polybenzimidazole composite membranes with phosphonated graphene oxide for high temperature polymer electrolyte membrane fuel cells. Journal of Power Sources, 412, 238-245 (2019).

https://doi.org/10.1016/j.jpowsour.2018.11.057

[26] Raptis D., Ploumistos A., Zagoraiou E., Thomou E., Daletou M., Sygellou L., Tasis D., Lianos P.: Co-N doped reduced graphene oxide as oxygen reduction electrocatalyst applied to photocatalytic fuel cells. Catalysis Today, 315, 31-35 (2018).

https://doi.org/10.1016/j.cattod.2018.02.047

[27] Yang H., Geng L., Zhang Y., Chang G., Zhang Z., Liu X., Lei M., He Y.: Graphene-templated synthesis of palladium nanoplates as novel electrocatalyst for direct methanol fuel cell. Applied Surface Science, 466, 385392 (2019).

https://doi.org/10.1016/j.apsusc.2018.10.050

[28] Zainoodin A. M., Tsujiguchi T., Masdar M. S., Kamarudin S. K., Osaka Y., Kodama A.: Performance of a direct formic acid fuel cell fabricated by ultrasonic spraying. International Journal of Hydrogen Energy, 43, 6413-6420 (2018).

https://doi.org/10.1016/j.ijhydene.2018.02.024

[29] Zhang J., Chen M., Li H., Li Y., Ye J., Cao Z., Fang M., Kuang Q., Zheng J., Xie Z.: Stable palladium hydride as a superior anode electrocatalyst for direct formic acid fuel cells. Nano Energy, 44, 127-134 (2018). https://doi.org/10.1016/j.nanoen.2017.11.075

[30] Ma T., Li C., Liu T., Yuan Q.: Size-controllable synthesis of dendritic Pd nanocrystals as improved electrocatalysts for formic acid fuel cells' application. Journal of Saudi Chemical Society, 22, 846-854 (2018). https://doi.org/10.1016/j.jscs.2018.01.007

[31] Mert S. O., Reis A.: Exergoeconomic analysis of a direct formic acid fuel cell system. International Journal of Hydrogen Energy, 41, 2981-2986 (2016). https://doi.org/10.1016/j.ijhydene.2015.12.029

[32] Samoilov V. M., Danilov E. A., Nikolaeva A. V., Yerpuleva G. A., Trofimova N. N., Abramchuk S. S., Ponkratov K. V.: Formation of graphene aqueous suspensions using fluorinated surfactant-assisted ultrasonication of pristine graphite. Carbon, 84, 38-46 (2015). https://doi.org/10.1016/j.carbon.2014.11.051

[33] Tkachev S. V., Buslaeva E. Y., Naumkin A. V., Kotova S. L., Laure I. V., Gubin S. P.: Reduced graphene oxide. Inorganic Materials, 48, 796-802 (2012). https://doi.org/10.1134/S0020168512080158 
[34] Fujimura M., Hashimoto T., Kawai H.: Small-angle Xray scattering study of perfluorinated ionomer membranes. 1. Origin of two scattering maxima. Macromolecules, 14, 1309-1315 (1981).

https://doi.org/10.1021/ma50006a032

[35] Danilov M. O., Slobodyanyuk I. A., Rusetskii I. A., Kolbasov G. Y.: Synthesis of reduced graphene oxide and its electrocatalytic properties. Russian Journal of Applied Chemistry, 86, 858-862 (2013). https://doi.org/10.1134/S107042721306013X

[36] Su H., Xu Q., Chong J., Li H., Sita C., Pasupathi S.: Eliminating micro-porous layer from gas diffusion electrode for use in high temperature polymer electrolyte membrane fuel cell. Journal of Power Sources, 341, 302-308 (2017).

https://doi.org/10.1016/j.jpowsour.2016.12.029
[37] Hong P., Luo F., Liao S., Zeng J.: Effects of Pt/C, Pd/C and $\mathrm{PdPt} / \mathrm{C}$ anode catalysts on the performance and stability of air breathing direct formic acid fuel cells. International Journal of Hydrogen Energy, 36, 8518-8524 (2011).

https://doi.org/10.1016/j.ijhydene.2011.04.081

[38] Lebedeva M. V., Yashtulov N. A., Flid V. R.: Metalpolymer nanocomposites with carbon fillers for the catalytic oxidation of formic acid. Kinetics and Catalysis, 59, 498-503 (2018).

https://doi.org/10.1134/S0023158418040043 